\title{
The Factors Behind Bulgaria's (Non) Convergence
}

\author{
Silvia Kirova \\ Senior Assistant Professor, PhD, University of National and World Economy, Sofia
}

\begin{abstract}
This paper looks at the real convergence of Bulgaria in the period 1999-2018 and tries to identify and describe the factors that have stimulated or impeded the growth and the convergence of the economy. The research is based on the sigma-convergence method for estimation of the disparities in terms of real GDP per capita among the six Central and eastern European (CEE) countries with a derogation and among them and the average euro area income per capita. A comparative analysis is applied when analyzing the factors for convergence and their evolution in the period as Bulgaria is compared to the other CEE economies. The results of the research show the presence of a sigma convergence in the observed period. The convergence has been more pronounces in the first ten years. Although Bulgaria demonstrates one of the highest growth rates, this growth has not been sufficient to close the significant income gap between Bulgaria and the EU and euro area averages. While some factors have played positive role in the convergence process, some weaknesses have not been overcome and continue to play negative role and impede the convergence.
\end{abstract}

Keywords: real convergence, convergence factors, Bulgaria

\section{Introduction}

In recent years Bulgaria has declared its intention to pursue entry into the ERM II mechanism and the country is in the process of implementing the necessary elements for an entry into it. As per the rules, it should be expected that after at least two years in the exchange rate mechanism, Bulgaria can be allowed to join the Economic and Monetary Union. Bulgaria fulfills all nominal convergence criteria, except the exchange rate criterion. But this is not the case for the state of real convergence. That's why the paper focuses on studying the degree of its real convergence in the last twenty years (1999-2018) and examines the factors, that have been drivers or impediments to the country's real convergence. The position of Bulgaria is compared to that of the remaining countries with a derogation from Central and Eastern Europe (CEE), as long as they are facing the same perspective the join the EMU in a certain point of time and because of the similarities between those economies and their economic development in the last twenty years.

Although real convergence is not a mandatory precondition for EMU membership, it is considered of great importance, because real convergence among monetary union member- states is a guarantee that they would not be affected by asymmetric shocks and if they are, they would respond symmetrically to the impulses of the single monetary policy.

The paper is structured as follows: the firs part represents a review of the theoretical concepts about real convergenceand the factors, driving convergence as well as a review of the empirical research of the Bulgarian real convergence; the second part describes the methodology; the third part reveals the state and the evolution of real convergence of Bulgaria, compared to that of the other $\mathrm{CEE}$ counties with a derogation and studies the factors for growth and convergence; the forth part concludes with a discussion of the results. 


\section{Theoretical background and empirical literature review}

The real convergence is a complex and multidimensional concept. It is evidenced by the fact that there is no single, universally accepted definition, neither a single method to measure real convergence. In the strict sense real convergence is the reduction of disparities in a group of countries in terms of income and labor productivity. In a much wider sense real convergence is understood as structural convergence where a homogenization of economic structures and homogenization towards higher levels of institutional quality is achieved. For example, Buiter (2005) defines real convergence as "convergence of productivity levels, real per capita income, structures of production and employment, financial markets and institutions, quality of regulatory and supervisory institutions".

The concept of convergence comes from the growth theory, which provides that countries, having lower income per capita levels are expected to grow faster than countries with higher income per capita levels. When this process takes place, the differences between countries diminish and they start to display greater similarity in terms of GDP per capita levels, thus achieving real convergence. The neoclassical growth models, based on research of Solow (1956) and Swan (1956) describe that the rate of growth is negatively corelated to the initial GDP per capita level. The main assumption in the models is for a diminishing marginal productivity of capital, which explains the fact that less capital-endowed countries display greater return on investment and hence greater levels of economic growth that allows for the catch-up process. In those models the technology is an exogenous factor and without technological change the convergence stops when the group of countries reaches their long- term steady-state. The fact that growth is driven by exogenous factors is a drawback of this first generation of growth models, that is overcome by the endogenous models of economic growth, that appeared in the eighties of the 20-th century. Those models explain that the economic growth can be sustained by technological change that is endogenous, i.e. can be driven by purposeful investments in scientific research or in human capital. In contrast to the previous models, the marginal productivity of capital does not decline, therefore the growth can be sustained. Some research, belonging to the endogenous growth models look at the technology distribution. The technological progress depends on the rate of innovation in the leading economies and the time needed for the other economies to copy the technologies. These models also predict convergence and higher growth rates for less developed economies, because it takes less time and resources to copy than to invent a technology.

These strands in the growth theory set the ground for the hypotheses of absolute and conditional convergence. According to the absolute convergence hypothesis, based on the neoclassical models, the poorer countries, that are capital-scarce and have lower initial income levels will always grow faster and catch up with the richer and capital intense countries. Given the only difference between them is the level of capital in the economy, all countries converge to a single, equal steady-state. In contrast, the conditional convergence hypothesis admits that the countries differ in their factor endowment and fundamental economic conditions and thus they do not converge to a single, equal steady-state, but each country converges to its own, specific steady-state. Thus, the growth rate is positively related to the distance between the starting level of income per capita and the country's own steady-state. The greater is the distance to the steady-state, the faster the country will grow. In this assumption, poorer countries are not necessarily supposed to grow faster than richer ones. They would grow faster, given they are away from their steady-state.

The different approaches to convergence explain the different methods to measure it. Sigma- convergence ( $\sigma$ convergence) is measured by the standard deviation of a given variable and its evolution in a given period. There is a sigma convergence when the standard deviation declines overtime. When applied to variables like GDP per capita or labor productivity, this method can be used to measure real convergence. A sigma-convergence in per capita income among a group of countries is an evidence of diminishing disparities between them. Beta-convergence ( $\beta$-convergence) on the other hand shows the speed with which a group of countries get closer to one another or to a reference value in terms of GDP per capita or labor productivity. An absolute beta-convergence exists when poorer economies grow faster than richer ones and catch up with them in terms of per capita income. It can be estimated by a regression, in which the 
rate of growth is regressed by the initial level of GDP per capita. The method of conditional beta-convergence allows to include different factors in the regression, that characterize the economies, so that we can understand their impact on growth and we can hold for the different steady-states. The presence of beta-convergence is a necessary but not sufficient condition for sigma-convergence. The faster growth of poorer economies will not necessarily lead to a reduction of disparities among the group.

It is worth noting that there is no common framework for identifying the factors that determine economic growth and hence convergence. We can approach the problem by looking at the above theories of convergence, which emphasize the importance of several factors for growth and by adding some other variables, taken from other economic theories and models, as well as empirical research, that play a role in the growth process. When looking at the neoclassical growth models, they put forward the availability of physical capital and labor supply as drivers of convergence. The endogenous growth models emphasize on the importance of innovation and investment in human capital as growth factors. The broader interpretation of additional theories and models allow for the inclusion of additional factors in the analysis.

An important factor for convergence, that is rooted in the growth theories is the availability of capital. The availability and the expansion of physical capital that contributes to the growth level is determined by the level of investments. The investments in the economy can be measured by the gross fixed capital formation (GFCF), inflows or stocks of foreign direct investments (FDI). GFCF is a measure of the net acquisition of fixed assets, or the domestic investments. On the other hand, the FDI inflows measure the investments from the rest of the world and they are associated with transfer of know-how and technology which stimulates technological progress and productivity increases in recipient economies. Some authors prove an unconditional positive relation between FDI and growth, while others show that there is a statistically significant positive relation only in the presence of other factors like quality of institutions, development of financial markets and quality of human capital.

Well-grounded in theoretical and empirical studies is the importance of labor force and human capital quality. On one hand, the trends in population growth, age structure, life expectancy and migration of population determine the availability of labor force. On the other hand, the quality of educational, health and social systems, as well as government policies affect the quality of human capital. In a study that covers 98 countries in the period 1960-1985, Barro (1991) reveals a significant positive link between the quality of human capital and economic growth. The human capital that accumulate knowledge and skills can increase the productivity of physical capital. The human capita quality can be characterized by variables like social expenditures for education, average years of schooling, labor force with secondary/tertiary education etc.

Technological progress is a growth factor, taken from the theory of economic growth. It enables the more productive use of factors of production. It can be studied by variables like gross domestic expenditures on research and development as percentage of GDP (GERD), people employed in the technological sector and others.

There are numerous studies, that reveal the importance of political and economic stability, quality of governance and institutions. Those factors are considered prerequisites for all other growth factors to play their role. Countries that have stable institutions that encourage factor productivity, innovation and investments display higher rates of economic growth. North (1990) determines institutions as rules of the game that set the limits to human behavior. As far as their influence for economic growth is concerned, institutions are crucial in guaranteeing protection of property rights, management of conflicts of interests, fight with corruption and effectiveness of macroeconomic policies. The quality of institutions is crucial for creating competitive market environment and attracting foreign capital. As far as macroeconomic stability is concerned, possible variables that can capture it are rate of inflation, budget balance, public government debt. Useful tools for analyzing quality of institutions are the indexes developed by international organizations or private institutes, that capture the quality of governance or the overall market environment. 
The financial system is also playing a role in the convergence process, given its function for efficient allocation of resources, asset prices formation and management of risks. More developed and deeper financial markets are expected to fulfill better their role of channeling savings into productive investment. For example, King and Levine (1993) study the importance of several indicators for the size and the depth of the financial system on economic growth. The empirical studies include variables like assets of the banking sector, market capitalization of listed companies, bank credit for the private sector, structure of the financial system and others to estimate the role of the financial system. The accumulated domestic savings are a factor for growth on their own, because they determine the level of investments. They depend, on one hand on the development of the financial markets, and on the other hand on demographic trends, productivity, income.

Economic openness, trade and economic integration have a role in the convergence process as well. Economic openness means that the residents can freely trade with the rest of the world and make investments abroad, and non-residents can also make investments in the domestic economy. The study of Di Giovanni and Levchenko (2009) find a positive relation between trade openness and economic growth. The openness is associated with better allocation of resources, due to specialization, economies of scale and transfer of technology. The length of membership into a regional economic block has a positive effect for the economic growth, more pronounced for poorer economies, as evidenced by a study of Crespo-Cuaresma, Dimitz and Grunwald (2002). The results are explained with the better access to technologies and financial resources that the poorer economies get with their inclusion into a regionally integrated market. The trade liberalization measures, associated with such regional integration give additional positive results. Variables that capture the importance of trade for growth are openness of the economy and change of export market share.

The real convergence of Bulgaria has been the subject of an empirical research in various studies. In a comprehensive research Grela et al. (2017) study the factors, driving the convergence process of six Central and Eastern European countries, including Bulgaria, towards EU15 in the period 1997-2014. The belief of the authors is that those six economies converge towards similar long-term steady-states. Using the absolute and conditional beta- convergence method, the research proves that there has been an absolute convergence in the observed period and that the process of convergence has been driven by the traditional growth factors as the level of investment in the economy and the human capital factor, but also by innovation activity and trade. The authors find that the dominant growth model for the region prior the Global financial crisis, based on large capital inflows of FDI has been exhausted overtime and the growth path of those economies is becoming more dependent on factors like innovation, quality of institutions and policies. In a similar vein a study by Zuk et al. (2018) identifies the factors for the convergence of Central Eastern and Southeastern economies in the period 2000-2016, emphasizing the growing role of quality of institutions, openness and external competitiveness. The empirical research also points out to the presence of convergence in terms of labor productivity among NUTS2 regions of CEE member states, as evidenced by Peshev and Pirimova (2020). Stateva (2015) identifies the conclusions that can be taken out from the euro adoption experience of the Baltic economies. More recent studies on real convergence of Bulgaria include Horatiu (2019) and Kaneva (2018).

\section{Methodology}

First, I use the sigma convergence method to identify whether there is a presence of real convergence in the period 2000-2018 among several Central and Eastern European states.

The countries chosen are Bulgaria, Czech Republic, Croatia, Hungary, Poland and Romania (given in alphabetical order). Those countries share some common characteristics, one of them being the fact that they all have the status of countries with a derogation and are expected to join the EMU in a certain moment. Another common characteristic of those countries is that the period after 1999 was marked by a transition from a command to a market economy, which significantly impacted their economic development and growth. 
I explore the convergence between the six countries and among the six countries plus and the euroarea, as I take the average GDP per capita value for the nineteen euroarea countries (EA19).

Further on I use a descriptive analysis to study the factors that have contributed or impeded the growth and the convergence process of Bulgaria. The factors considered are those identified in the previous section of the article. The primary source of statistical information is the Eurostat database. An analysis is made of the development of those factors during the period 1999-2018 and to the extent relevant, comparisons have been made with the other CEE countries with a derogation.

Findings for the state of real convergence and the factors for real convergence

\section{Real convergence}

During the observed period Bulgaria's real GDP per capita has been growing faster than that of the euroarea. The period can be divided into two subperiods of 10 years, with the Global financial crisis being the break between them. In the subperiod 2000-2008 Bulgaria's real GDP per capita grew by 6,7\% annually, while for the same period EA19 grew by only $1,5 \%$ average annually. This period was marked by preparation for the accession of Bulgaria to the European Union in 2007. The positive expectations associated with it, as well as the favorable global economic conditions contributed to the significant growth. The peak growth was registered in 2005 , when GDP per capita grew by $7,7 \%$. The same trends were observed in the other derogation countries. The record growth was registered by Romania in 2004 and in 2008 when its GDP per capita grew by $11,1 \%$. Unfortunately, the Global financial crisis and the economic slowdown that followed interrupted the catch-up process and the subperiod 2009-2018 was characterized by much lower growth rates. The euroarea was severely hit by the sovereign debt crisis which resulted in very low growth rates. The average annual growth rate for EA19 was $0,55 \%$ for 2009-2018. For the same period Bulgaria's real GDP per capita grew by 2,48\% annually. The biggest growth rate was registered in 2011 when the GDP per capita grew by $4,9 \%$. Among the other countries Romania displayed the highest growth rate in 2017 when it grew by 7,7\%.

Taking the whole period concerned, Bulgaria displayed an average annual growth of $4,5 \%$, which is the second highest among the compared countries, with Romania being the best performing economy in terms of growth (4,69\%). Among the countries observed Croatia has registered the lowest average economic growth. At the same time the EA19 grew by only $1 \%$ annually. The fact that Bulgaria and Romania grew about 4 times higher than the Euroarea allowed the economy to catch up and close the gap in the living standard.

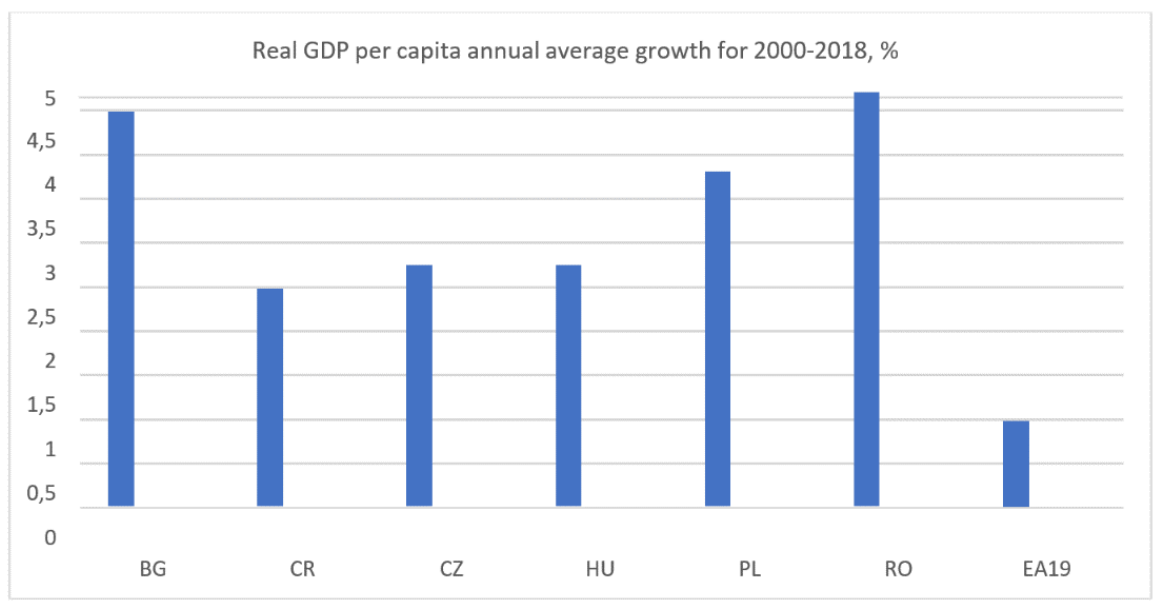

Figure 1. Real GDP per capita annual average growth for the period 2000-2018. 
The fact that the two countries with the lowest income per capita have achieved the highest growth rates is signifying of a convergence process to have taken place. As depicted in Figure 2 the period has been marked by a sigma-convergence, as evidenced by the declining values of the relative standard deviation of real GDP per capita for the 6 CEE economies and for the 6 CEE economies + EA19. This implies that in the period 2000-2018 the income disparities between the six CEE countries as well as between them and the average euroarea income have been reduced. The convergence process in both cases has been much faster in the first subperiod. The convergence lines till 2008 are much steeper and after 2008 they become flatter, meaning that the Global financial crisis has impacted negatively the convergence process.

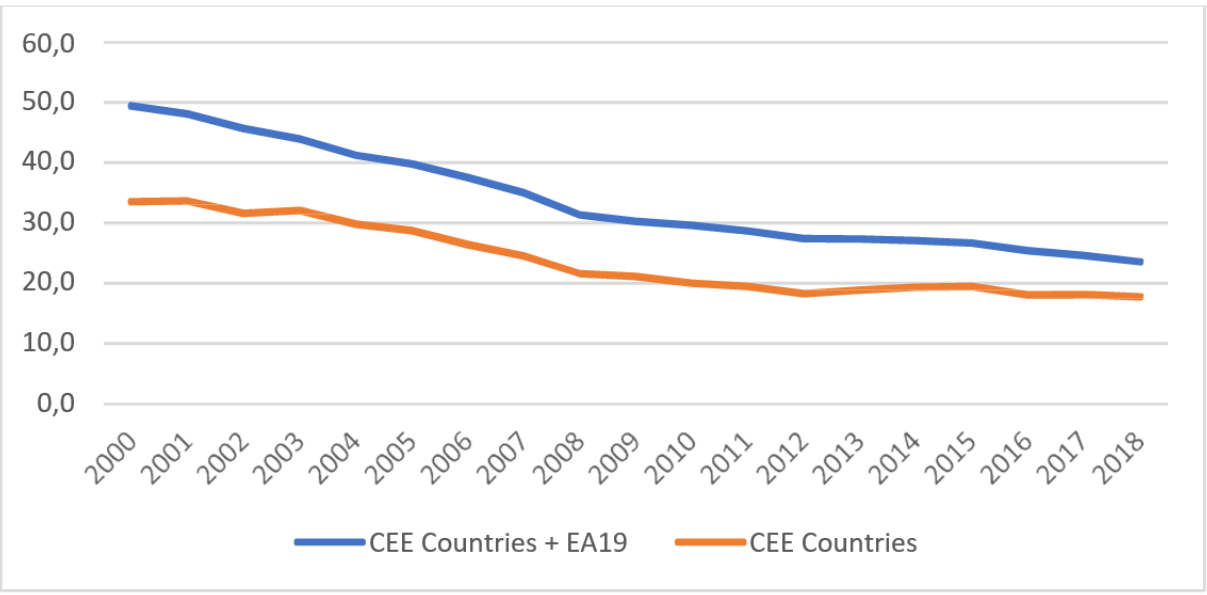

Figure 2. Relative standard deviation (\%) of real GDP per capita in PPS in 2000-2018.

Despite the presence of convergence, Bulgaria remains the worst performing among the countries with a derogation in terms of GDP per capita. In 2000 its GDP per capita stood at only $29 \%$ of EU 27 average, while at the same time Czech GDP per capita stood at $73 \%$ of EU average. The only country that performed worse in 2000 was Romania with GDP per capita at $26 \%$ of EU average. But till the end of the period Romania has significantly advanced and its GDP per capita level in 2018 stands at 65\% of EU average, while Bulgaria's GDP per capita reached half of EU average (Figure 3.).

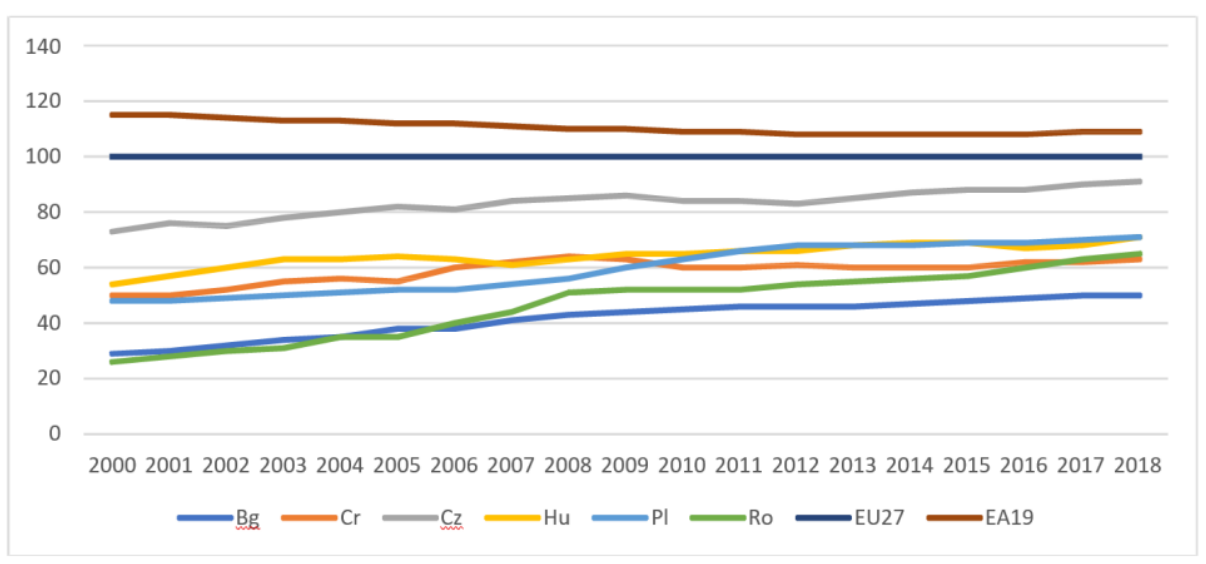

Figure 3. Purchasing power adjusted GDP per capita in 2000-2018 (EU 27=100). 
The same holds for the state of real convergence in terms of labor productivity, measured by GDP perperson employed. In 2018 Bulgaria's labor productivity was $47,4 \%$ of EU 27 average. Bulgaria displays the lowest labor productivity when compared to the other derogation countries. Romania and Hungary that follow next have labor productivity in 2018 of $68,2 \%$ and $69,4 \%$ of EU average respectively. In Czechia the labor productivity has reached $83 \%$ of the EU level in 2018.

The convergence that have taken place seems was not sufficient for closing the income and productivity gaps between CEE economies and the EU averages, particularly in the case of Bulgaria. Partially it is because of the very low initial position of Bulgaria in the beginning of the period, and it will take a long time to see its income converging to the EU average. But looking at figure 3 it seems that despite the similar starting positions, the growth patterns differ from country to country. While Bulgaria and Romania start from the same point and share the same convergence path till 2008, both countries follow different paths in the second subperiod and Romania's income per capita exceeds the Bulgarian one. The same holds when comparing Croatia and Poland and the development of their income per capita over time. Therefore, the factors driving the convergence and their different manifestation in the economies should be taken into consideration.

The drivers or impediments to convergence

\section{The availability of capital in the economy}

The capital is a key driver of economic growth as per the neoclassical theories and in the endogenous theories of growth. The GFCF in Bulgaria in 1999 is just $16,3 \%$ of GDP and it grows steadily to reach its highest point of $33 \%$ of GDP in 2008. Afterwards it declines to reach $18,8 \%$ of GDP in 2018. It is below the level of investments in peer economies, except for Poland and below the EU and Euroarea averages (around 21\%). The GFCF have had positive contribution to economic growth in Bulgaria in most of the years of the period explored, except for the years 2009-2011 and 2016. The business sector is the main contributor for the investments in the economy. The manufacturing sector plays the most important role in recent years. While construction sector has been important contributor in the past, its role has been

diminished in recent years. The investments in transport and storage and other services sectors have also increased. The public sector investments represent on average 4\% of GDP for the period after 2007 and about two third of public investments are based on EU funds.

The investments from the rest of the world have played a major role for Bulgarian convergence, especially in the first subperiod. The FDI inflows have increased significantly in the first ten years of the observed period and in 2007 they reached EUR 9 billion, which represent $31,2 \%$ of GDP (given just $6,05 \%$ of GDP in 1999). Then they declined to $1,9 \%$ in 2014 and stabilized at around 4\% of GDP in 2018.

The analysis of the data points out to the low levels of investments in the economy that prevent the accumulation and renewal of capital stock and the introduction of new technologies. The declining trend of domestic and foreign investments in the second subperiod has hindered the growth prospects for Bulgaria. The dependence of Bulgarian economy on FDI and on EU funds to sustain growth is also evident.

\section{Labor force and human capita quality}

Labor force and human capital quality are key factors for growth and drivers of convergence. Unfortunately, the demographic developments in Bulgaria, that determine the availability of labor force are negative. During the whole period observed the crude rate of total population change ${ }^{1}$ that combines the natural population change and the migrations is negative. Bulgaria is one of the few EU countries in which the natural change and net migrations are both negative. The

1 The crude rate of population change is the ratio of population change to the average population during a given year, expressed per 1000 persons. 
severity of the situation in Bulgaria can be compared to that in Romania, and to a less extent to that in Croatia and Hungary. On the other hand, Czech Republic and Poland have positive crude rates of total population change. The projections of UN 2017 show that the Bulgarian population is going to contract by $0,8 \%$ annually and in 2050 it is going to be 5,4 million people (down from 7,05 million as of January 1,2018) and the working age population is going to contract even faster. The negative trends predetermine labor shortages in industry, construction and services.

Overall the activity rate has risen from $60,7 \%$ in 1999 to $71,5 \%$ in 2018 . Behind that positive general trend, a serious problem for Bulgaria is that the activity rate and employment among certain groups of the population is very low, namely among the low-skilled, living in rural areas and the Roma. The lack of integration of those groups in the labor market can be serious impediment that can hinder future growth prospects. Bulgaria shows one of the highest rate in the EU of young people (aged 15-29) that are not in education, employment or training.

The educational attainment is a key factor determining the employment prospects and therefore the labor force availability and its quality. The percentage of people aged 15-64 that have successfully completed upper secondary education has increased gradually from $48,9 \%$ in 1999 to $53,6 \%$ in 2018 , and of those that have completed tertiary education have increased from $15,1 \%$ to $24,8 \%$ in the same period. The share of people employed, that have completed tertiary education to the total employment has also risen from $23,2 \%$ in 2000 to $31,7 \%$ in 2018.

Despite those positive developments there are some other facts that can hinder future growth. Bulgaria is among the EU countries that records high level of early school leaving $(12,7 \%)$, which is particularly high for rural regions and the Roma population. Furthermore, an European Commission report (European Commission, 2019) reveals that Bulgaria shows significant gaps in the acquisition of basic and digital skills. As far as the basic skills are concerned, the PISA annual surveys disclose the share of underachieving 15-year-old students. In 2018 in Bulgaria nearly 44\% of 15-year-olds lack basic knowledge in mathematics, $46,5 \%$ in science and $47,1 \%$

in reading, which is almost double the EU averages. The situation is similar in Romania, while other derogation countries, especially Czech Republic and Poland show better results, than the EU averages. Bulgaria has the highest share of population among EU countries without any digital skills (37\%). Digital skill levels are also low among the young, as $45,7 \%$ of people aged $16-24$ do not have basic digital skills, compared to the EU average of $18,1 \%$.

The above data presented shows that the negative demographic developments and low achievements regarding human capital quality may have played negative role over the last twenty years. Active measures on the labor market and in the education and healthcare system would be needed to overcome those negative developments and improve the quality of human capital in the future.

\section{Political and macroeconomic stability, and quality of institutions}

During the whole period Bulgaria displays macroeconomic stability, when judged by macroeconomic variables like inflation rate, budget balance and government debt to GDP ratio. After a severe episode of hyperinflation in 1997 Bulgaria introduced a currency board arrangement which contributed for installing and sustaining macroeconomic stability. By fixing the Bulgarian lev to the Deutschemark mark in 1997 and then to the Euro in 1999, the monetary policy discretion was surrendered, and the monetary policy sources of inflation disappeared. This move helped reduce inflation from $10,3 \%$ in 2000 to $2,3 \%$ in 2003 . The period of high economic growth since 2003 till 2008 was marked by increase in inflation rate, which reached its highest level of $12 \%$ in 2008. For the subperiod 1999-2008 the average annual inflation rate of Bulgaria is $6,75 \%$, compared to $2 \%$ in the EA19. The positive inflation differential can be explained by the high aggregate demand, significant FDI inflows, high commodity prices, labor market developments and excise taxes harmonization. It also reflects the catching up status of the Bulgarian economy. After the Global financial crisis, the inflation was substantially reduced. In the subperiod 2009-2018 the average annual inflation rate of Bulgaria was $1,15 \%$, compared to $1,25 \%$ for EA 19 . 
The rules of the currency board contributed to the health of government fiscal position as well. For the whole period of 20 years there are only two years (2009 and 2014) in which the government budget deficit exceeded the level of $-3 \%$ of GDP. As far as the government debt to GDP ratio is concerned, Bulgaria started the period with a level of $75 \%$ which was gradually reduced to $13 \%$ of GDP in 2008. Afterwards it started to increase slightly till 2014 , when the collapse of the Corporate and Commercial Bank burdened the government finances and the debt to GDP ratio reached 27\%. In 2018 the debt to GDP ratio of Bulgaria is $22,3 \%$, which is the third lowest in EU next to Estonia and Luxembourg. It is worth noting, that after 2001, Bulgaria has sustainably maintained a level of debt to GDP below the threshold of $60 \%$ and a level that is much lower than the EA19 average, which is an evidence of fiscal discipline.

Another factor that influence economic growth and hence convergence is the size of the government sector, measured by the final consumption expenditure of the government as a percent of GDP. Although the empirical research is ambiguous in its findings, most of the papers point to a negative relation between the government size and the economic growth. The government spending in Bulgaria has been reduced from $41,7 \%$ in 1999 to $36,5 \%$ of GDP in 2018 and it is lower than the average for EA19 (47\% in 2018).

The Heritage Foundation Index of Economic Freedom measures the government policies effectiveness and economic conditions and compares them among 186 countries around the world since 1995. This is a composite index that measure the economic freedom based on 12 qualitative and quantitative indicators, grouped into four broad categories: rule of law (property rights, government integrity, judicial effectiveness), government size (governments spending, fiscal health and tax burden), regulatory efficiency (business freedom, labor freedom, monetary freedom) and open markets (trade freedom, investment freedom and financial freedom).

Bulgaria's overall score has improved substantially for the period under review. In 1999 Bulgaria's score was 46,2, while in 2018 it is 68,3 and thus for two decades Bulgaria has moved from being repressed to moderately free economy. In recent years the indicators that drag us down are government integrity and effectiveness of the judicial system that show no improvement. In the beginning of the period it was the government spending, fiscal health and monetary freedom that weighted most heavily on our score but were significantly improved during the years. Comparing the index to that of other CEE derogation countries we see that Bulgaria's score is better than that of Croatia $(61)$ and Hungary $(66,7)$ and worse than that of Czech Republic $(74,2)$, Poland $(68,5)$ and Romania $(69,4)$. Among the countries observed, Czech Republic has the highest score, belonging to the mostly free economies. The remaining economies all belong to the moderately free economies category, with Croatia having the lowest score.

Another index measuring the quality of the market environment is the Doing Business Index of the World Bank. It is a good measure of the effectiveness of business regulations. In 2018 Bulgaria ranked 50, ahead of Croatia which ranked 51 (among 190 countries around the world). At the same time Poland ranked 27, Czech Republic 30, Romania 45 and Hungary 48. The problematic areas for the country are starting a business and getting electricity due to lengthy procedures and ineffective institutions.

As the first index shows the effectiveness of the judicial system is a weak point for Bulgaria. Since its accession to the EU in 2007, Bulgaria (and Romania as well) was put under scrutiny, because of further needed progress with the judicial reform, fight with corruption and organized crime. It is through the Mechanism for Cooperation and Verification (CVM) that the European Commission monitors the progress in those areas. A proof of the failure of institutions to tackle those problems is the fact that the CVM for Bulgaria, eighteen years after its introduction is not yet suspended. The failure in this filed plays its negative role on the efficiency of institutions and the regulatory process. Because of this the competitiveness of the economy is also hindered. Therefore, the political and macroeconomic stability are a good prerequisite for economic growth, but they need to be supplemented by further efforts regarding the effectiveness the judicial system and streamlining the administrative processes. The postponement of the needed reforms has hindered the Bulgarian growth up to this moment and would compromise the growth prospects in the future. 


\section{Economic openness, trade and economic integration}

Bulgaria is a small open economy. The economic openness has been steadily growing from $78,2 \%$ in 2000 to $131,2 \%$ in 2018 (despite a temporary decline during the Global crisis). All CEE countries with a derogation are open economies too, displaying trade to GDP ratio above the world average in 2018 of $59,4 \%$, with Hungary (166\%), and Czech Republic (150\%) being most open and Romania having the lowest degree of openness to trade (86\%). At the same time Bulgaria's export market share has also grown from $0,08 \%$ in 1999 to $0,18 \%$ of world exports in 2018. For the 2012-2017 the export market share has been increased by $15 \%$, predominantly for basic metals and minerals, machinery and equipment and services as well.

Bulgaria is well integrated into the internal market of the EU, which is its main trading partner. In 2018 nearly $68 \%$ of Bulgaria's exports is for EU and $69 \%$ of imports is from EU countries. In 2007 when Bulgaria joined he EU the respective shares were $61,1 \%$ for exports and $51,7 \%$ for imports.

Further to the above positive developments the net exports have had positive contribution to the GDP growth in the second subperiod. Overall, the economic openness and the integration of the Bulgarian economy into the EU market has played a beneficial role for the convergence in the observed period.

\section{The technological factor}

As far as the technological factor is concerned the GERD in Bulgaria have increased over the last twenty years from 0,54\% of GDP in 1999 to $0,75 \%$ in 2018 . It is only Romania with GERD of $0,51 \%$ of GDP in 2018 that stands behind Bulgaria. The averages for EU27 and EA19 are 2,19\% and 2,22\% respectively. Among the derogation countries the Czech Republic reports the highest GERD of $1,93 \%$ in 2018.

During the period under review the number of employed in high-technology manufacturing and knowledge intensive sectors has risen in absolute terms and as a share of total employments. While in 2000 the employment in these sectors stood at about $3 \%$ of the total employment, in 2018 it is 3,9\%, which is comparable to the EU and EA19 average level of 4\%. At the same time Hungary and Czech Republic have the highest share of employment in the technology sector $-5,2 \%$ and $5 \%$ respectively. Croatia has a similar level as Bulgaria. Poland and Romania have lower levels of about $3 \%$ of total employment.

Since 2007 Cornel University in collaboration with INSEAD and World Intellectual Property Organization issue a Global Innovation Index, trying to capture and compare 126 countries around the world in terms of their innovation activities. The overall score is an average of variables that try to capture inputs (elements of the national economy that enable innovation) and outputs (the results of that activity). In 2018 Bulgaria ranks 37 in the world ahead of Poland (39), Croatia (41) and Romania (49) and behind Czech Republic (27) and Hungary (33). In 2007 when the index was published for the first time Bulgaria was ranked $81^{\text {th }}$, and in the 2008- 2009 edition was $74^{\text {th }}$, behind all the other derogation countries.

In the European Innovation Scoreboard for 2018 Bulgaria is on $27^{\text {th }}$ place of all 28 EU members then (with only Romania behind), with its innovation performance being below $50 \%$ of EU average. The problematic areas that determine this position are weaknesses in categories like financial support for innovation, links between companies and research institutions and attractive research systems.

Despite the improvements in the field during the observed period, Bulgaria has still much work to do. An increase of the GERD towards the EU and euroarea averages would have simulative effect for growth. 


\section{The financial system}

The financial system plays an important role in the economy by channeling accumulated savings to their most productive uses. During the observed period, the Bulgarian financial sector has functioned smoothly, except for the episode with the collapse of the fourth biggest bank in Bulgaria in 2014. This episode revealed some weaknesses of the banking supervision, performed by the Bulgarian National Bank and measures were taken afterwards to correct those defects.

The assets of the banking system have expanded from 15,9\% of GDP in 1999 to $60,9 \%$ in 2017 . The peak was reached in 2009 when banking assets were $72,9 \%$ of GDP and then they started to decline slightly. In parallel to those developments the bank credit to the private sector has risen significantly from $11 \%$ to GDP in 1999 to $51,3 \%$ in 2018 . The highest level was reached in 2009, when the bank credit to the private sector stood at $69 \%$ of GDP. After the Global financial crisis, a mild moderation was achieved. Those developments were accompanied by accumulation of certain imbalances like the rise of the share of non-performing loans to total loans and the increase in the level of private sector debt. The consolidated private debt in 1999 was only $16,6 \%$ to GDP and during the period of high growth preceding the Global crisis it mounted to $140,4 \%$ in 2008 and 2009 . Afterwards the value was gradually reduced to $95 \%$ of GDP in 2018 . The share of non-performing loans has fallen as well but it remains among the highest in Europe.

Overall the developments in the financial system have been beneficial for the growth and convergence of Bulgaria.

\section{Discussion of the results}

The research on the Bulgaria's real convergence in the last twenty years shows that even though Bulgaria registers one of the highest average growth rates among the countries in consideration it has not managed to close the serious income gap. In the end of the period Bulgaria remains the poorest EU economy with its real GDP per capita and its labor productivity being half of the EU averages. During the period the disparities in terms of real GDP per capita between the six CEE countries with a derogation have been reduced as well as the disparities among them and the euroarea average per capita income. The convergence process has been more pronounced during the first subperiod and sluggish in the second subperiod.

This situation poses serious questions about the factors that have stimulated or impeded the convergence process in Bulgaria, on one hand. On the other hand, the situation poses the question as to whether it is appropriate for Bulgaria to pursue an EMU membership, given the low level of real convergence.

The analysis of the factors for convergence show that some factors have played a beneficial role in the convergence process, namely the macroeconomic stability, the improvement of the market environment, the increased trade and economic openness and the integration of the economy into the EU market, as well as the development of the financial market. At the same time some other factors have unambiguously exerted negative effect on the convergence process. The failure in the reform of the judicial system and the fight with corruption, the inability to make the administrative procedures more effective and reduce the administrative burden on businesses have negatively impacted the competitiveness of the Bulgarian economy. While in the period till the Global financial crisis the positive economic developments globally and the enthusiasm from our EU entry managed to mask those problems, their destructive effect became more pronounced afterwards. The drastic reduction of the FDI after 2007 as well as the low level of the domestic investments, heavily dependent on the EU funds drag the convergence process. The negative demographic developments and the low achievements in human capital quality have inarguably played against the Bulgaria convergence. While some progress has been achieved regarding the technological factor, Bulgaria still needs to advance. This points out to the actions and the reforms that should be undertaken to see Bulgaria converging to the EU and euroarea. 
On this background it seems reasonable to question the intention of Bulgaria to join the EMU given its low level of income convergence. For the sake of comparison, when Slovakia, Estonia, Latvia and Lithuania joined the EMU in $2009,2011,2014$ and 2015 respectively, they had a GDP per capita of $72 \%, 71 \%, 64 \%$ and $76 \%$ of EU average. I argue that joining the EMU would not have any destabilizing effects for Bulgaria and for the euroarea, as long as Bulgaria, being under a currency board arrangement for more than twenty years is in a currency regime that mimics the currency union. The EMU entry will allow Bulgaria to share the benefits of the single currency not only its costs. At the same time the macroeconomic stability, the lack of serious macroeconomic imbalances and the small size of the economy is a guarantee that a premature entry will not destabilize the euroarea.

\section{References}

[1] Barro, R. (1991). Economic Growth in a Cross-Section of Countries. The Quarterly Journal of Economics Vol. $106(2), 407-443$.

[2] Buiter, Willem H. (2005). To purgatory and beyond. When and how should the accession countries from Central and Eastern Europe become full members of the EMU. In Breuss, F. and Hochreiter, E. (Eds.). Challenges for Central Banks in an Enlarged EMU (pp. 145-186). Vienna and New York: Springer.

[3] Crespo Cuaresma, J., Dimitz, M. and Grunwald, D. (2002). Growth, convergence and EU membership. Oesterreichische Nationalbank Working Paper No. 62, April 2002.

[4] European Commission. (2018). European Innovation Scoreboard. [Online] Available: https://ec.europa.eu/growth/content/european-innovation-scoreboard-2018-europe-must-deepen-itsinnovation-edge_en.

[5] European Commission. (2019). Country Report Bulgaria 2019, Including an In-Depth Review on the prevention and correction of macroeconomic imbalances. [Online] Available:

https://ec.europa.eu/info/sites/info/files/file_import/2019-european-semester-country-reportbulgaria_en.pdf.

[6] Grela et al. (2017). Is Central and Eastern Europe Converging towards EU-15. NBP Working Paper 264, Narodowy Bank Polsky, Warsaw 2017.

[7] Horatiu, D. (2019). Joining the Eurozone - an exploration of real and structural convergence in Romania, Bulgaria and Croatia. Economic Archive 1/2019.

[8] Kaneva, A. (2018). An Assessment of the Bulgarian Economy Degree of Convergence with the Economies of the EU Member-States in the 2006-2014 period, Economic and Social Alternatives, Issue 11/2018, 6989.

[9] King, R., Levine, R. (1993). Finance and Growth: Schumpeter might be right. Quarterly Journal of Economics 108, 717-737;

[10] North, D. (1990). Institutions, Institutional Change, and Economic Performance. Cambridge: Cambridge University Press.

[11] Peshev, P. and Pirimova, V. (2020). Beta and sigma-convergence of productivity in NUTS2 regions in the (EU) member states from the CEE region. Economic Alternatives, Issue 1, 79-90.

[12] Solow, R. (1956). A contribution to the theory of economic growth. The Quarterly Journal of Economics, Volume 70,65-94.

[13] Stateva, I. (2015). The Baltic Economies and the Marked out Route to Membership in the European Monetary Union. Economic Studies Journal, Issue 1, 68-89.

[14] Swan, T. (1956). Economic Growth and Capital Accumulation, The Economic Record, Volume 32 (2), 334361.

[15] United Nations. (2017). World Population Prospects. [Online] Available: https://esa.un.org/unpd/wpp/Publications/Files/WPP2017_KeyFindings.pdf.

[16] Zuk, P., Polgar, E., Savelin, L., Del Hoyo, H., Konig, P. (2018). Real Convergence in Central, Eastern and Southeastern Europe. ECB Economic Bulletin., Issue 3. 